\title{
2.6 \\ BLÅMÅLAREN - HÄLSINGLANDS MEST \\ KÄNDE OIDENTIFIERADE MÅLARE
}

\author{
Anders Assis
}

I detta kapitel görs ett försök att identifiera Blåmålaren, en av Hälsinglands mest kända men hittills oidentifierade folkliga målare. Intresset för Blåmålarens efterlämnade interiörer, som de i världsarvsgården Pallars i Långhed, har varit stort, men målarens identitet har gäckat forskningen. Starka indicier talar för att Blåmålaren möjligen kan identifieras som Mäx Jonas Andersson och hans hustru Finn Karin Matsdotter från Bingsjö i Dalarna. De var ett gift par som flyttade runt i Hälsingland under 1840-talets andra hälft för att sedan bosätta sig permanent i Alfta socken. Spridningen av de verk som på stilistiska grunder kan tillskrivas Blåmålaren följer denna familjs rörelser i landskapet. Dessutom finns ett verk utfört av Blåmålaren vilket går att knyta till familjens sociala närhet: en målad rakspegel från Ljusdal. Därtill finns några porträtt i Bingsjö kapell, som på arkivaliska grunder kan påvisas som verk av Mäx Jonas Andersson och som har stora likheter med Blåmålarens manér. För att tydliggöra sammanhangen blir det nödvändigt att skärskåda dessa och andra verk, samt att ingående studera familjen Andersson/Matsdotters liv. Detta bringar en mängd detaljer i dagen, som sammantagna ligger till grund för denna hypotes. I indiciekedjan ingår analyser av pigment och färgämnen hos några av de undersökta verken. Samtidigt kommer detta kapitel att visa att ett alltför ensidigt fokus vid en målares användning av enskilda pigment kan låsa tankebanorna och skymma ett större sammanhang. Det kommer att visa att likaväl som att en hantverkare kunde växla sin motivmässiga repertoar, så kunde materialanvändningen skifta över tid. Säkerligen var det många bakomliggande orsaker som kunde påverka vilka material som anskaffades. 


\section{Blåmålaren i forskningen}

År 1953 lyfte Manne Östlund fram Blåmålarens verk i sin beskrivning av en av inredningarna i Pallars: "I Långhed, Alfta, har en mästare med tydlig förkärlek till uppdrivna blå och gröna färger målat några fantastiska stadsbilder [...]" (Östlund 1953:88). Det är också genom denna inredning från 1853 (fig. 1) som Blåmålaren är mest känd.

Ingemar Svensson och Hilding Mickelsson myntade pseudonymen Blåmålaren, grundat på den starkt blå nyans som de dokumenterade $\mathrm{i}$ flera av de inredningar som de på stilmässiga grunder tillskrev denne (Svensson \& Mickelsson 1967:27, fig. 65-70).

Figur 1 (2.6.1):

Måleri från 1853 i sängstugan på Pallars, Långhed, Alfta. Foto:

Anders Assis
Utöver inredningarna i Pallars finns ytterligare tre interiörer på ursprunglig plats i Alfta som har tillskrivits Blåmålaren. Ett målat rum i gården Bråna i Gundbo vilket är daterat 1859, en del av en interiör i Nygårds i Näsbyn från 1861 och en odaterad inredning i gården Hammar i Nordanå (LjM, Kerstin Sinhas arkiv). Utöver dessa finns ytter-

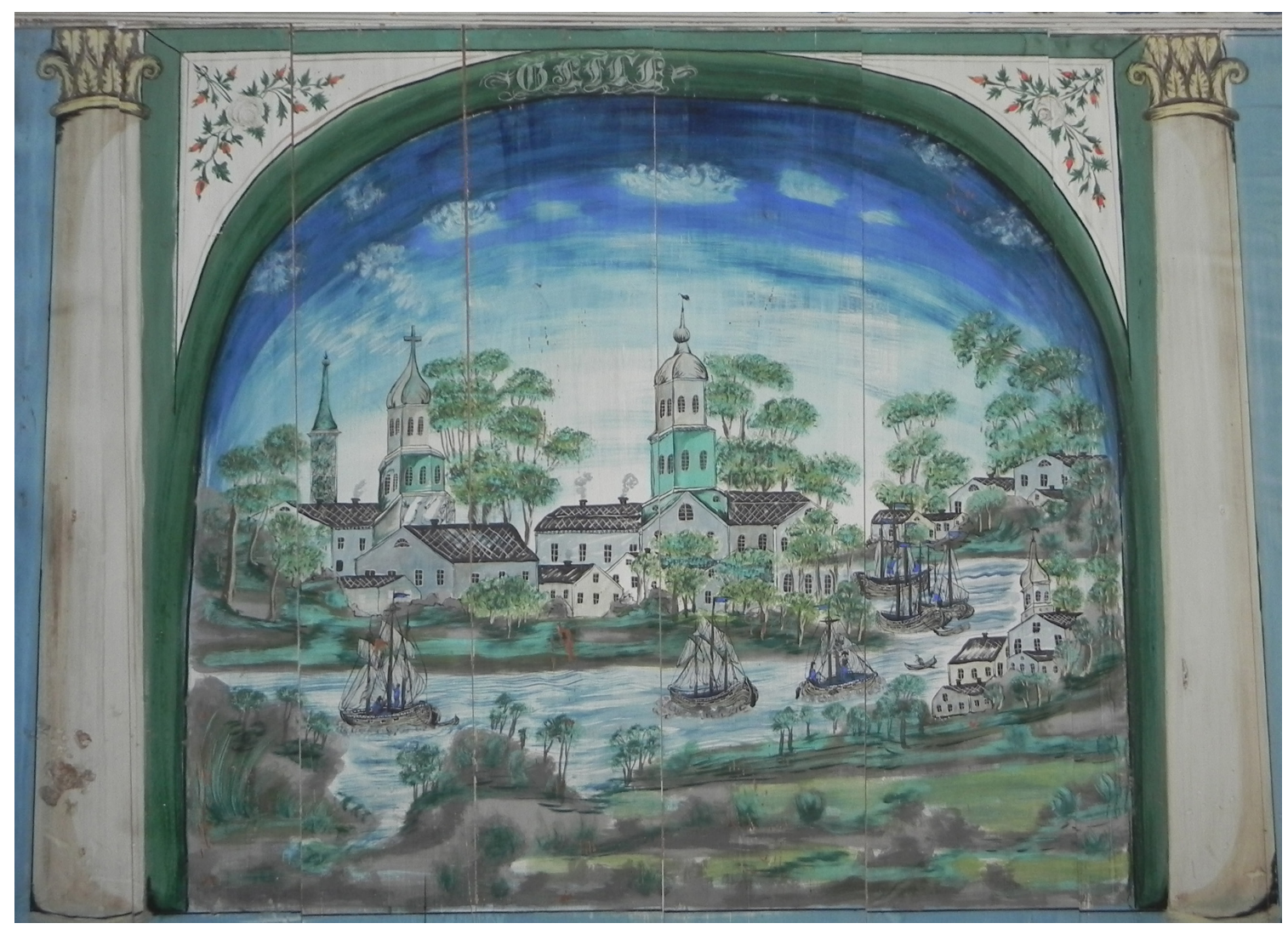


ligare två odaterade, numera nedplockade inredningar bevarade, vilka dock saknar fullständiga provenienser. En av dem finns i Söderhamns museums samlingar men kommer ursprungligen från Ovanåker eller Alfta (SH 2053). Den andra finns i Nordiska museets samlingar med ursprung från byn Nordanå i Alfta socken (NM 177369).

Alla dessa målerier har så stora likheter i sina utföranden, i handlag, detaljer och helheter att de utan tvivel bör kunna härledas till en och samma målare. Likheterna till trots, finns det samtidigt avvikande detaljer och manér i åtminstone några av dem. Dessa är så pass signifikanta att det reser frågan om det kan röra sig om flera upphovsmän som haft ett tätt samarbete.

Verken som har tillskrivits Blåmålaren är alla tillkomna under en mycket begränsad tidsperiod, med dateringar mellan 1853 och 1861 . Användningen av det starkt blå pigmentet har setts som en gemensam nämnare för alla Blåmålarens verk, men frågan är om inte just detta fokus har hindrat vidare attribueringar. Hälsinglands bönder utmärkte sig genom att bygga och modernisera förhållandevis ofta. De var i allmänhet noga med att följa det för orten aktuella inredningsidealet och det har visat sig att kringvandrande målare vanligen fick anpassa sin repertoar till detta. Att en hantverkare på 1800-talet under dessa förhållanden konsekvent skulle ha favoriserat ett pigment genom hela sin verksamhetsperiod är knappast ett rimligt antagande. Den blå färgen kan lika gärna ha varit ett inslag i ett övergående mode, vilket då skulle kunna förklara varför alla de tidigare attribuerade verken är tillkomna under en period av endast åtta år. Kulörer och använda färgpigment är inte bara något som berättar om ekonomi och tillgångar, utan kan i likhet med motiv och mönster i såväl måleri som textil ses som uttryck för mer eller mindre tidsbundna modetrender. Genom att frigöra sig från ett fokus på det blå pigmentet, samt genom att lyfta blicken ut från Blåmålarens sedan tidigare kända verksamhetsområde i Voxnandalen, så blir det möjligt att attribuera fler verk till samma målare.

\section{Blåmålaren i Alfta, Delsbo och Ljusdals socknar}

Genom konnässörskapsanalys kan ytterligare verk tillskrivas Blåmålaren, såväl inredningar som lösa föremål. Från Ljusdals socken finns tre sådana målade inredningar. De är sedan tidigare dokumenterade, men har aldrig sammankopplats med Blåmålaren. En av gårdarna, Bommars i Letsbo, har sina inredningar kvar i ursprungligt skick. De två andra 
inredningarna är endast bevarade i fragment: måleri på papper från gården Ol-Mårs i Sjöbo, i Ljusdalsbygdens museums samlingar (Ljm 9219) och måleri på brädor från Pell-Pers i Noresbo, i privat ägo. I inredningen från Ol-Mårs förekommer även den starkt blå färgen på ett sätt som liknar Blåmålarens användning i Alfta.

Världsarvsgården Bommars, eller Oppigården som hemmanet Letsbo $\mathrm{nr} 2$ kallades tidigare, har två mangårdsbyggnader. De är bägge uppförda åren 1846-1848 (LjM, Harald Grundells arkiv; Berg et al. 2002), efter att en brand den 9 maj 1845 hade lagt den tidigare bebyggelsen i aska (Ljusdal KI:6:180). En av byggnaderna har flera interiörer bevarade från mitten av 1800-talet och allt talar för att byggnaden inreddes i direkt anslutning till bygget, då det hölls ett bröllop i släkten kort därefter (Berg et al. 2002:48ff). En klädstuga på övervåningen, tapetserad med tidningsmakulatur, bör ha inretts något år senare då tidningarna är daterade 1840-1851. I en vardagsstuga på bottenvåningen, den så kalllade Västgötastugan (Berg et al. 2002:58), är väggarna brädklädda och schablonmålade. Dateringen "Mållat 1848" finns på en väggfast säng som tillhör denna ursprungsinredning. Stilen på dessa bokstäver och

Figur 2 a-c (2.6.2 a-c): Jämförelser av målade typsnitt. Från Pallars i Alfta (ovan och mitten) och Bommars i Ljusdal (under). Foto: Anders Assis
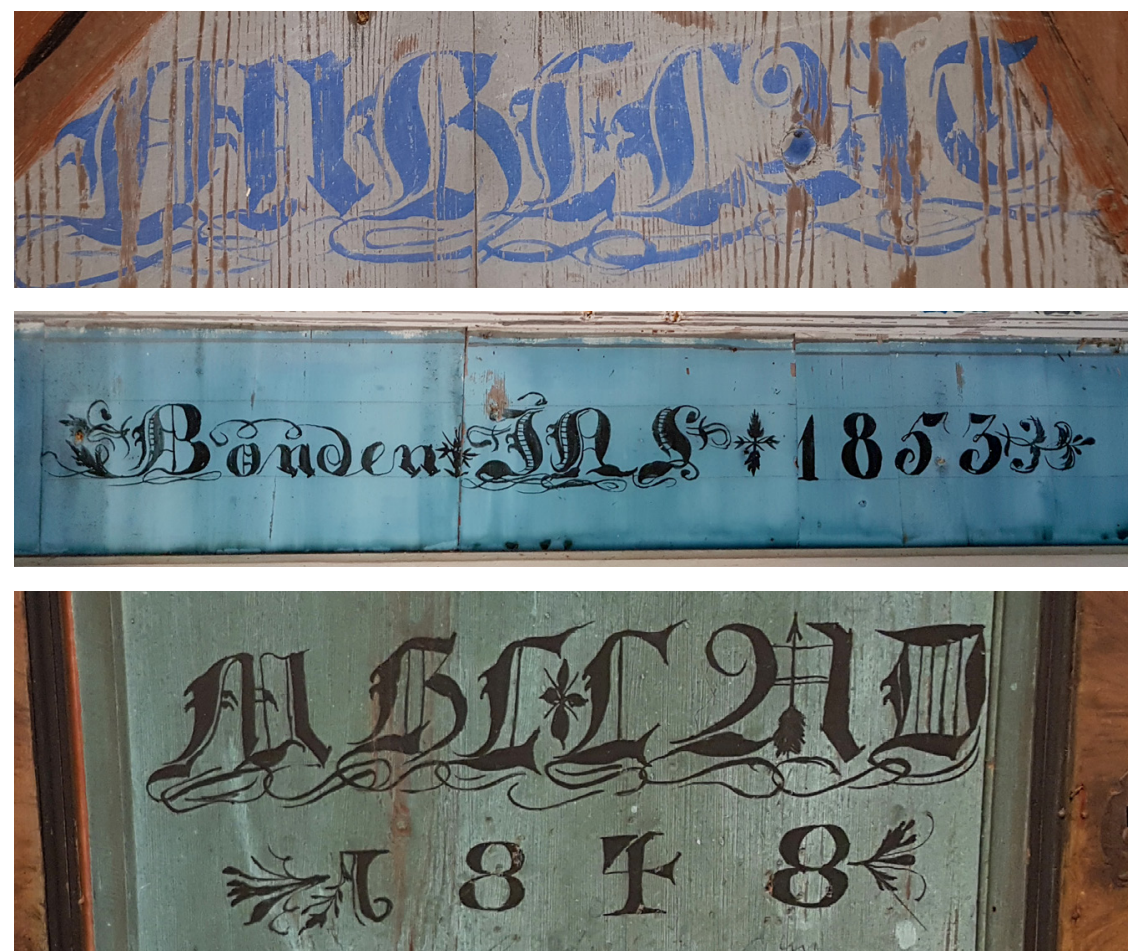
siffror bär flera karaktäristika som går att identifiera som Blåmålarens handstil, såsom den förekommer i Pallars i Alfta (se fig. 2). Bokstäverna i frakturstil är baserade på det vid tiden moderna typsnittet Old English, men målaren har adderat egna karaktäristiska detaljer.

Byggnadens övriga inredningar består av såväl frihandsmåleri som schabloner och tryckta tapeter. Rummen i Bommars utgör helheter där alla inredningsdetaljer, även omfattande färgsättningen på en kakelugn, har vägts mot varandra vilket visar att de är resultat av mycket medvetna val. Salens intressanta kombination av handtryckta tapeter och schablonmåleri har tidigare lyfts fram (Broström 2011) och dess inslag av högreståndskaraktär vittnar om delvis andra estetiska ideal än dem som normalt dominerade folkliga inredningar. Just detta är utmärkande för delar av Hälsinglands inredningskonst vid denna tid. Inredningarnas helheter, i kombination med den snabba byggprocessen, kan tala för att en och samma person ligger bakom flertalet av gårdens inredningar.

Flera av rummen i Bommars har inslag av marmoreringar utförda på ett sätt som känns igen från Pallars. Även vissa av de använda schablonerna visar samma mönster som motsvarigheterna i Pallars. Generellt sett bör stor försiktighet iakttas innan schabloner används för att påvisa en specifik upphovsman. Det är oftast inte tillräckligt tillförlitligt. Schabloner kopierades, och i många fall går det att visa att ett och samma schablonmönster använts av flera olika identifierade målare. Just dessa schabloner är även de kända från fler ställen och bland annat har Svärdes Hans Ersson (1828-1910) från Rättvik (Andersson 1996:137f) använt mycket liknande schablonmönster i inredningar i Voxnandalen. Icke desto mindre styrker schablonernas förekomst i just detta fall sambandet mellan Bommars och Pallars, som del i den helhet där många olika detaljer sammanfaller.

Inredningarna från Ol-Mårs i Sjöbo, vilka också finns fotodokumenterade 1929 av Harald Grundell på ursprunglig plats (NM EU 861), kan även de kopplas till Pallars och därigenom även till Bommars, genom bokstävernas och siffrornas former. Inte bara tecknens former utan även upplägget av dateringen känns igen från Pallars. De är gjorda med varierande typsnitt och enligt ett mönster som gör att de avviker från alla andra kända dateringar i Hälsingegårdsinteriörer. Utöver den daterade inredningen från Ol-Mårs, vilken bär årtalet 1846, finns också en farstuinredning från samma byggnad med en väggmarmorering ut- 

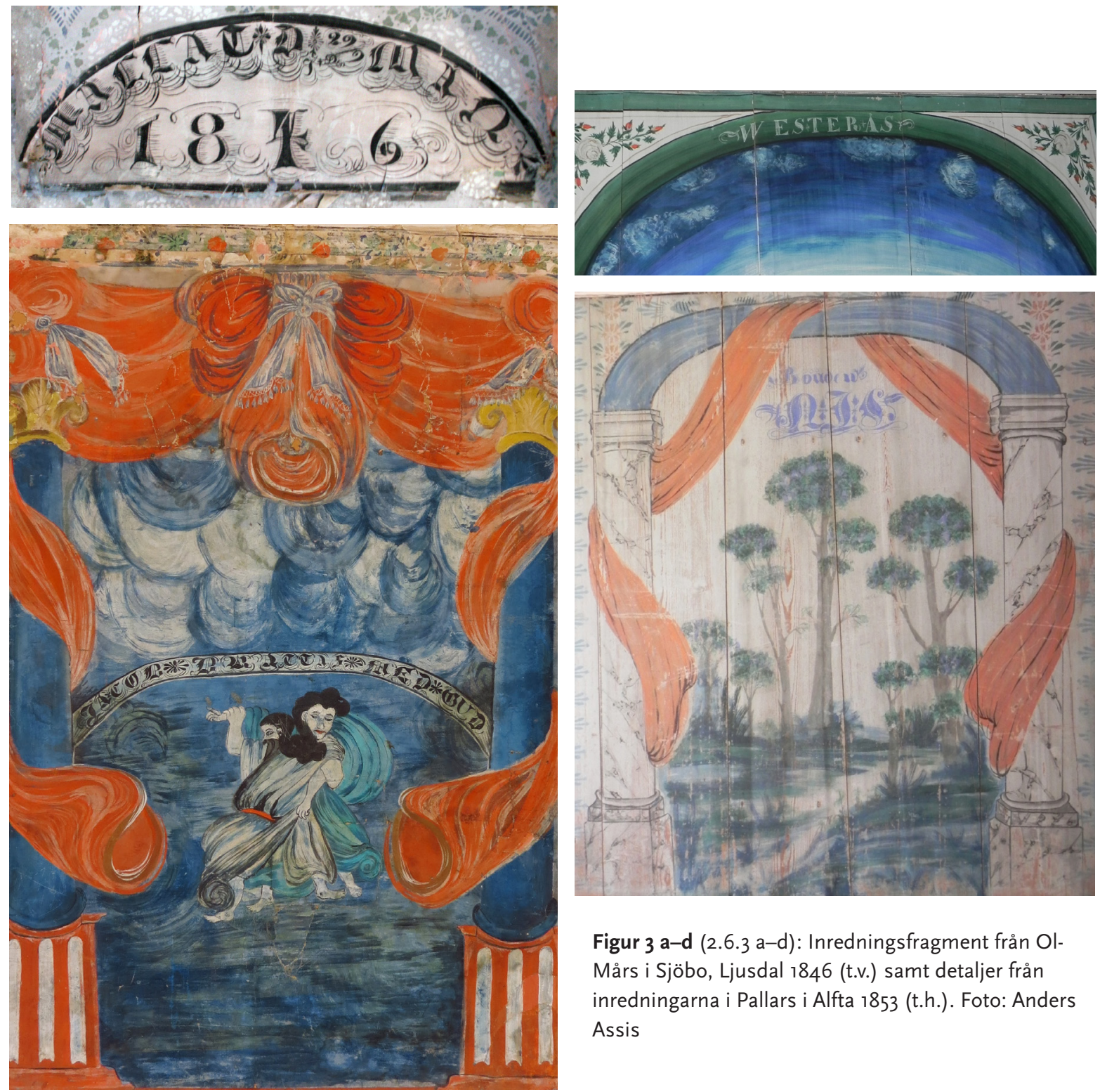

Figur 3 a-d (2.6.3 a-d): Inredningsfragment från OlMårs i Sjöbo, Ljusdal 1846 (t.v.) samt detaljer från inredningarna i Pallars i Alfta 1853 (t.h.). Foto: Anders Assis

förd med samma uttryck som de i Bommars. I Ol-Mårs centralmotiv som föreställer "Jakob brottas med Gud", finns också en stor del av de kännetecken som återfinns i Blåmålarens Alftainredningar (se fig. 3). ${ }^{8 \circ}$

80. Från Ol-Mårs finns en nedtecknad muntlig tradition där uppgiftslämnaren antog att målaren Ädel från Ljusdal kan ha målat i gården. I gården doku- 

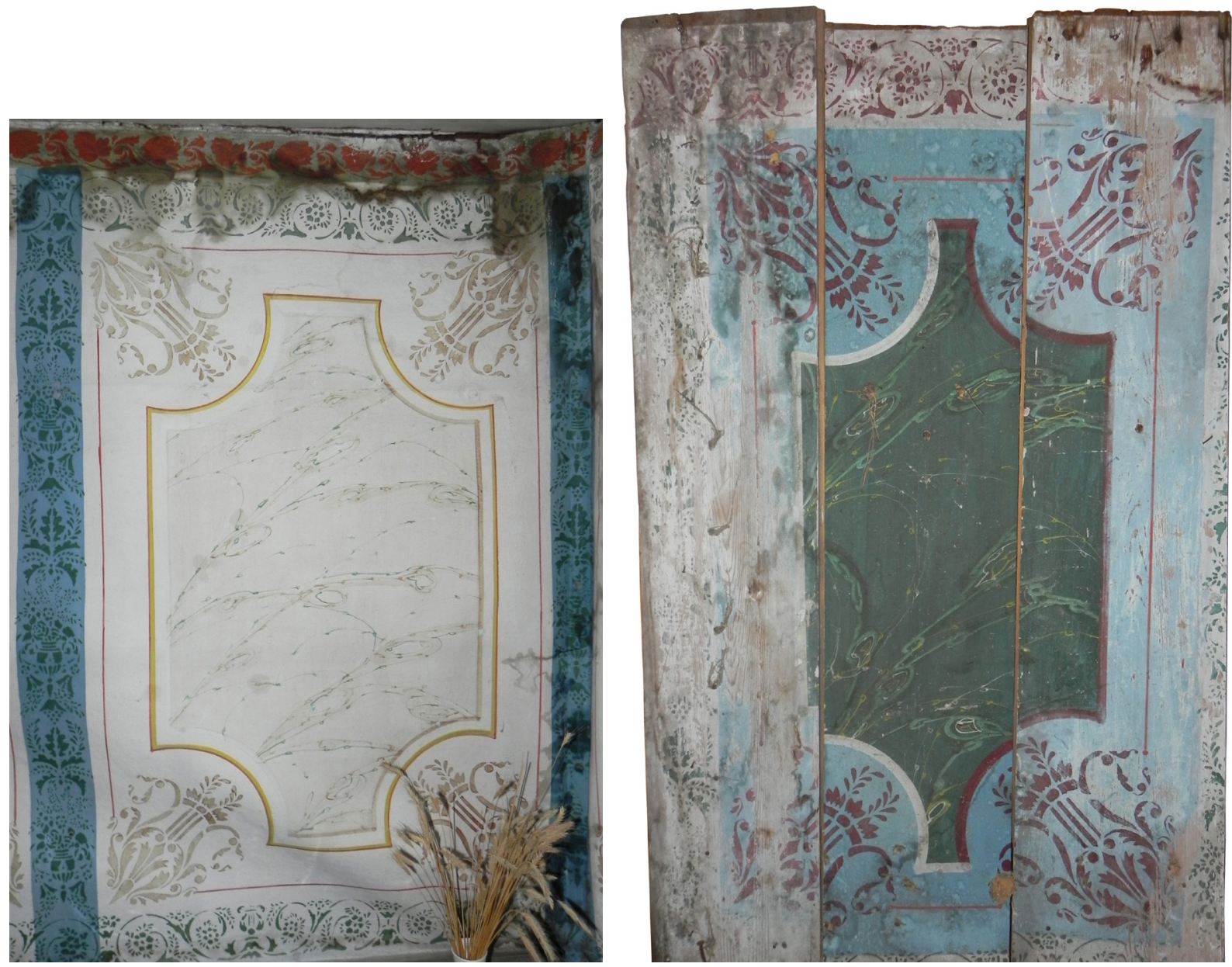

Måleriet från Pell-Pers i Noresbo fogas till de övriga genom sin fullständiga överensstämmelse med det som finns i Bommars framkammare (se fig. 4). Även marmoreringsstilen känns igen från Ol-Mårs.

Utöver interiörerna från Ljusdal finns även en inredning i fragment från en okänd gård i Bredåker i Delsbo socken, bevarad i Nordiska museets samlingar (NM 160807) som även den på stilmässiga grunder kan

menterades ett skåp till vilket det finns antecknat: "Skåp enligt förmodan målat av Ädel" (NM foto 172 O.m.). Skåpets måleri är av den typ som lokala målare brukade utföra, men det har inget stilmässigt sammanhang med gårdens väggdekorationer. Det kan även konstateras att uppgiftslämnaren var osäker, vilket kom till uttryck i formuleringar som "det var före min tid, men jag antar att han [Ädel] målat här..." Dessa dokumentationer gjordes 1929 av Harald Grundell (NM EU 861 samt LjM, Harald Grundells arkiv).

Figur 4 a-b (2.6.4 a-b): Väggfält med marmorering och schabloner i Bommars framkammare (t.v.) och från PellPers (t.h.). Foto: Anders Assis 

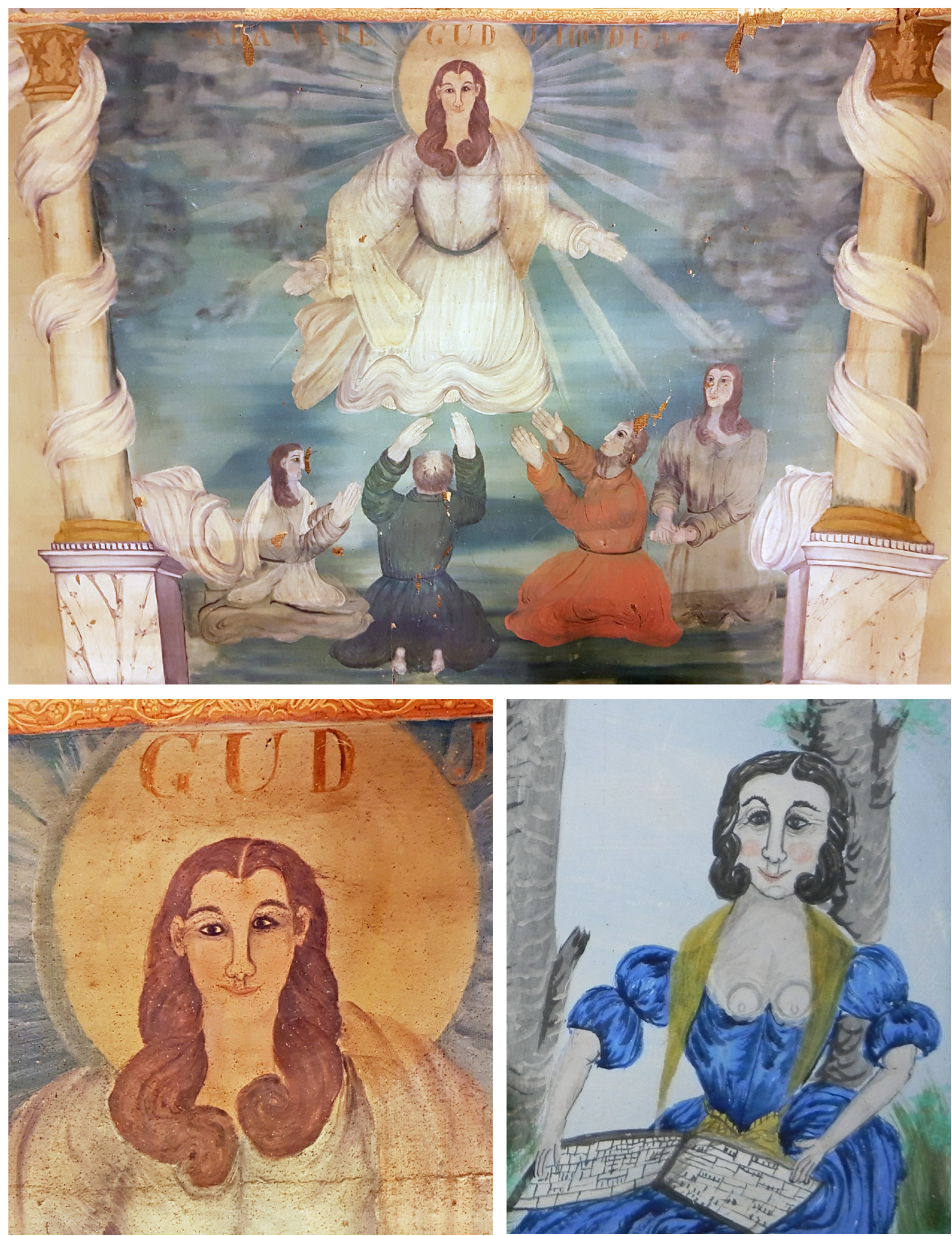
knytas till Blåmålaren. Genom figurframställningen går denna att sammankoppla med Alftainredningarna (se fig. 5). Figurerna och många andra detaljer kopplar den även till inredningen från Ol-Mårs i Sjöbo. Enskilda bokstavsformer i texten påvisar likheter med motsvarigheter i Bommars och flera av de andra inredningarna.

Förutom dessa inredningar finns från Ljusdal och Delsbo ett antal lösa föremål, utförda i Blåmålarens manér. I Ljusdals socken finns från 1847 ett skrin märkt "EOD" ${ }^{81}$ samt en kånkask och ett laggkärl bägge märkta "BJHD". ${ }^{82}$ Från 1848 finns där även den ovan nämnda rakspegeln märkt "AJS", ${ }^{83}$ samt ett schatull märkt "JAS". ${ }^{84}$ Dessa föremål överensstämmer således tidsmässigt med Ljusdalsinteriörernas dateringar som bär årtal mellan 1846 och 1848. Delsboinredningen är som nämnts odaterad, men ett skrin från socknen med årtalet 1850 , i Delsbo hembygdsförenings samlingar, går genom blomstermåleriet och bokstävernas former att koppla till Blåmålarens alster i såväl Alfta som Ljusdal. Från Alfta finns en odaterad rullgardin dokumenterad (Svensson \& Mickelsson 1967:95) och på världsarvsgården Pallars finns en spinnrock daterad 1852. Denna är försedd med målade initialer "BOD", vilket torde utläsas som Brita Olsdotter ${ }^{85}$ och avse den kvinna som blev ingift i gården vid denna tid. Spinnrocken är målad året innan måleriet i sängstugan på gården utfördes.

Samtliga dessa föremål liknar varandra på flera punkter vad gäller manér och stilelement (se fig. 6). Flera detaljer i de tidigare beskrivna inredningarna återkommer även i senare måleri. Genom de korsvisa referenserna stärks intrycket av ett föremålsbestånd med ett måleri som till stora delar kan härledas till samma upphovspersoner. Spår efter Blåmålarens manér går därmed att belägga i Ljusdal mellan åren 1846 och 1848 och i Delsbo 1850 samt i Alfta från 1852 och framåt.

Genom naturvetenskapliga analyser har det varit möjligt att påvi-

81. Målad till okänd person. I privat ägo. Har funnits i samma släktgård i Ljusdal under hela 1900-talet.

82. Målade till Brita Johansdotter, f. 1807 i Bäckebo, Ljusdals socken. Fortfarande i släktens ägo.

83. Målad till Anders Jonsson, f. 1826 i Grophamre, Ljusdals socken. Fortfarande i släktens ägo.

84. Målad till okänd person. I privat ägo. Har funnits i samma släktgård i Ljusdal åtminstone sedan 1800-talet.

85. Målad till Brita Olsdotter f. 1825 i Näsbyn, Alfta socken och gift till Pallars 1851. Fortfarande i släktens ägo. 


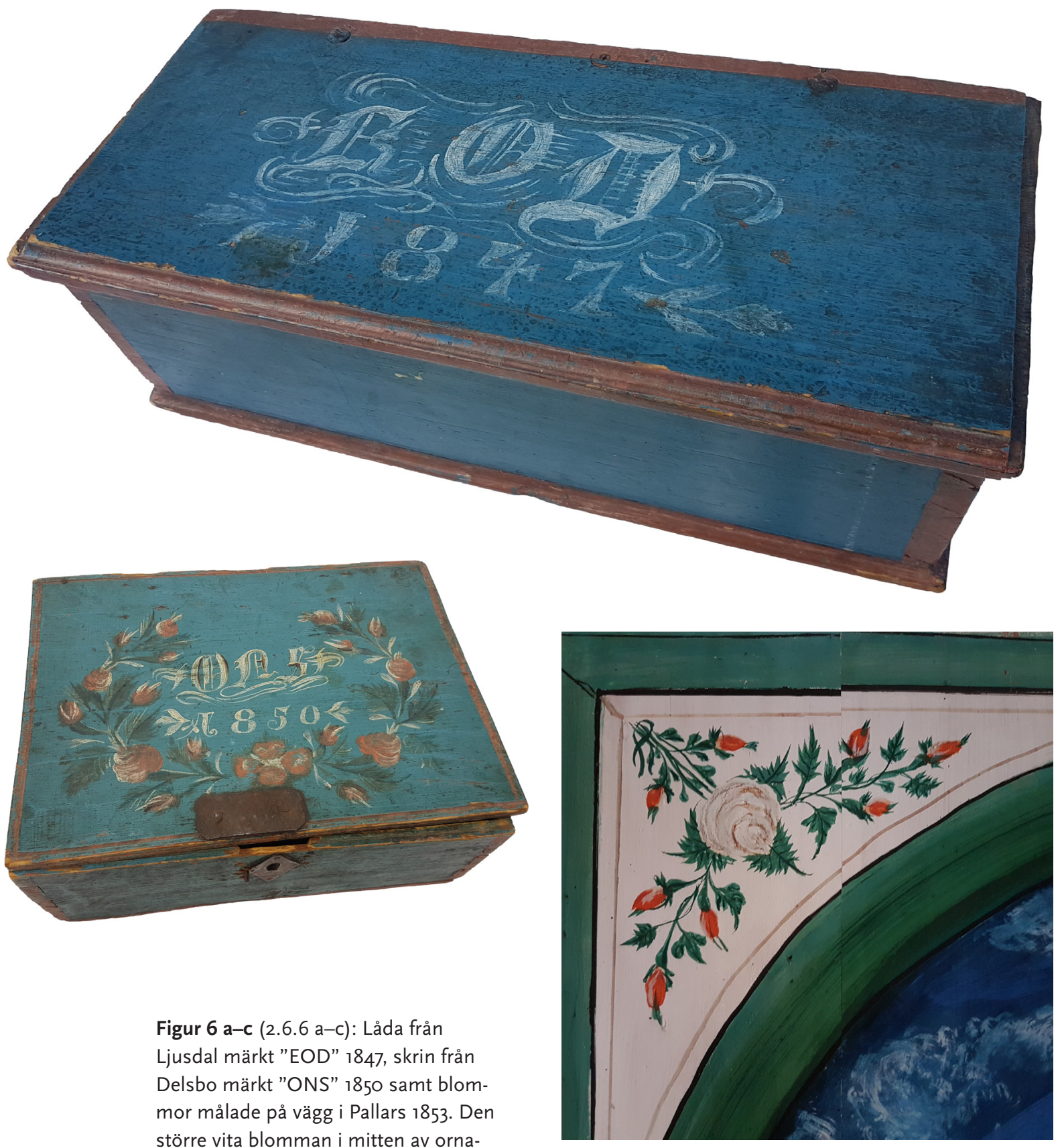
större vita blomman i mitten av ornamentet i Pallars har förlorat sin färg genom blekning. Färgämnet har möjligen ursprungligen varit rött. Bokstäver och siffror kan även jämföras med de i Bommars och Pallars i figurerna 2 och 3. Foto: Anders Assis 
sa likheter i målarfärgernas sammansättningar i de olika objekten, se vidare kapitel 3.5 Konstteknologiska undersökningar av hälsingemåleri. Den specifika starkt klarblå kulören som gett namn till målaren har visat sig vara syntetisk ultramarinblå, tillgängligt på en bredare marknad efter 1800-talets mitt (jfr Nyström 2012). Pigmentet förekommer dock i få av hans tidigare verk. Målarmaterialet kan ge belägg för det som de stilistiska karaktärsdragen indikerar. Många nya syntetiska pigment kommer ut på marknaden vid denna tid. Det är inte förvånande att en och samma målare kan ha varierat sin färgrepertoar. Blåmålarens skicklighet och preferenser tycks ha utvecklats efter hand samt påverkats av växlande mode och ideal, vilket har bidragit till en variation i såväl det estetiska uttrycket som den material-tekniska kvaliteten i olika verk. Variationerna kan även ha berott på ekonomi, ersättningen för arbetet och tid till förfogande.

\section{Blåmålaren - en kringvandrande familj?}

Tidigare forskning har konstaterat att Blåmålarens ursprung torde kunna sökas i Dalarna (Broström 2011). Inget av det kända och här presenterade materialet talar mot detta. Från gården Pell-Pers i Noresbo, Ljusdal, finns det en uppteckning som kan kopplas samman med inredningen från samma gård. Harald Grundell upptecknade där 1929 uppgifter efter gårdsägaren Nordström: "Målningarna äro gjorda av dalfolk. Det var en man och en kvinna som följdes åt och målade i gårdarna här" (LjM, Harald Grundells arkiv). Här finns således en ledtråd som skulle kunna förklara de ibland disparata dragen i Blåmålarens manér: att det faktiskt kan röra sig om mer än en målare, som arbetade tillsammans. ${ }^{86}$

Det finns en genom arkivfynd sedan tidigare känd målarfamilj som väl passar in på den geografiska spridning som Blåmålarens verk uppvisar. Familjen, som tidigare har lyfts fram av Manne Östlund, Christer

86. Från Pell-Pers finns två olika inredningar dokumenterade, men uppgiften om dalmålarna knyts inte till någon särskild av dessa två. Uppteckningen torde dock avse den yngre av inredningarna, som här ovan har attribuerats till Blåmålaren. Den äldre inredningen utfördes av den Ljusdalsfödde målaren Hindriks-Olle (1793-1861) med assistans av Anders Erik Ädel (1809-1888) (Assis 2017, för bild se Andersson 2000, fig. 119-120). Gårdsfolket 1929 var födda på 1870- och 1880-talen och den muntliga traditionen hade uppenbarligen endast bevarat minnet av det senare inredningstillfället. 
Bergin och Roland Andersson, bestod av dalmålaren Jonas Andersson (1820-1905), hans hustru Karin Matsdotter (1820-1897) och deras sex barn (Östlund 1953; Bergin 1965; Andersson 1996). Familjen som från 1842 till 1864 var skriven i Bingsjö var endast hemma på husförhör vissa år. De vistades mycket i Hälsingland och deras uppehållsorter kan delvis följas genom kyrkböckernas notiser. Samtliga Blåmålarens kända daterade verk följer familjens förflyttningar i landskapet. Att de inte tidigare har kopplats till Blåmålaren beror troligen på att Jonas Andersson sedan tidigare har satts i samband med ett verk vars måleri har ett annat uttryck, läktarmålningarna i Bingsjö kapell. Vi återkommer till dem. En genomgång av allt tillgängligt källmaterial kan dock visa att han rimligen inte är upphovsman till det.

Jonas Andersson och hans familj skrivs, beroende på varierande bostadsorter under olika delar av sina liv, med flera olika gårdsnamn: Mäx, Finn, och Knuts. För läsbarhetens skull används dock i denna text konsekvent Mäx, eftersom det är under detta namn Jonas Andersson tidigare är omnämnd i litteraturen.

Mäx Jonas Andersson föddes den 4 juli 1820 i en familj som enligt vad kyrkböckerna förtäljer uppenbarligen förde ett kringvandrande liv. Fadern Mäx Anders Andersson (f. 1799) var från Mora men sedan 1820 gift till Lenåsen i Boda kapellförsamling och Rättviks socken med Knuts Anna Jonsdotter (f. 1796). Familjen förefaller aldrig ha varit hemma i Boda på husförhör (Boda AI:6a:56, AI:7a:63 samt AI:8a:61) och Jonas yngre bror Daniel var född 1834 i Bjärtrå socken (Bjärtrå C:3:57). Vad familjen gjorde på resande fot är inte känt, men den uppenbara tolkningen måste vara att de försörjde sig som kringvandrande arbetare.

Jonas var dock hemma i Boda själv åren 1834-1835 varefter han flyttade till Falun. I november 1835 flyttade han som lärling in hos tapetseraren Melcher Widén (1803-1848) och var skriven där till och med 1841 (Falu Kristine AI:18:149, AI:20:71, AI:23 1847-1856:72 samt BII:1). Han flyttade då, titulerad "tapetserargesäll", åter till Rättvik och hemgården i Lenåsen. År 1842 flyttade han vidare till Bingsjö i samband med att han gifte sig med Finn Karin Matsdotter.

Karin Matsdotter var född den 22 april 1820 i Bingsjö, Boda kapellförsamling i Rättviks socken. Föräldrarna, Danils Mats Olsson (17901830) och Finn Brita Ersdotter (1782-1852), var bönder på moderns föräldrahem, dit fadern hade gift sig 1810 (Rättvik E1:1:193). Fadern var sjuklig och familjen förefaller ha varit stadigvarande hemma. Efter faderns död togs hustrun ur mantalslängden (Bingsjö-Dådran AI:1:7). 
Jonas Andersson och Karin Matsdotter gifte sig 1842 i Bingsjö och året efter fick de sonen Anders Johan. Denne står antecknad som född i Rättvik, men efter detta förefaller det som om familjen vistades långa perioder i Hälsingland även om de alltjämt var skrivna hemma i Bingsjö. Hushållet betecknas som fattigt och de står som "inhyses" under Karins föräldrahem, som brukas av en svåger och en syster till Karin (Bingsjö-Dådran A I:2:12). År 1845 befann de sig i Ovanåker där sonen Gustaf föddes och 1847 i Ljusdal när dottern Anna Brita kom till världen. Källmaterialet förtäljer att de även 1849 vistades i Ljusdal, genom en notering i hemförsamlingens husförhörslängd. Detta visar att det var känt på hemorten var de befann sig, vilket kan antyda att familjen hade vistats där stadigvarande under någon period.

Året efter hade de dock begett sig till grannsocknen Delsbo, där sonen Per Erik föddes 1850. Några år senare, 1853 , föddes dottern Johanna i Alfta socken men dog ung. År 1856 angavs i Bingsjös husförhörslängd att familjen "bo i Alfta". Åren 1858 till 1864 antecknades vidare i samma källmaterial: "inhyses i Alfta", där också barnen August och Johanna föddes 1857 respektive 1864. Familjen skrevs slutligen i Alfta där de också stannade för gott, bortsett från äldste sonen Anders som senare flyttade åter till Bingsjö.

Sammanfattas detta så ger det bilden att familjen vistades i Ovanåker 1845 , i Ljusdal 1847 och 1849, i Delsbo 1850, i Alfta 1853 och från 1856 och framåt, även om de vissa år även vistades i perioder i Bingsjö. Materialet kan vidare antyda att de inte vandrade runt och arbetade, utan snarare att de kan ha varit mer eller mindre stationära under kortare eller längre perioder på sina vistelseorter. Åtminstone gäller detta för perioderna i Ljusdal respektive Alfta. Familjens rörelsemönster mellan olika orter i Hälsingland uppvisar en slående överensstämmelse med de daterade alster som här ovan via konnässörskapsanalys har knutits till Blåmålarens manér. Detta talar för att familjen Mäx Jonas Andersson och Karin Matsdotter möjligen kan vara identiska med Blåmålaren, och det enda som talar mot detta är att Mäx Jonas Andersson tidigare har knutits till ett måleri med ett helt annat uttryck: det på läktarbarriären i Bingsjö kapell. En undersökning av källmaterialet från Bingsjö omkullkastar dock teorin om att läktarmålningarna i Bingsjö skulle vara utförda av honom. 


\section{Mäx Jonas Andersson och målningarna i Bingsjö kapell}

Den enda kända källa som knyter Jonas Andersson till något specifikt verk är Bingsjö kapells räkenskaper från 1843. Där framgår det att Andersson fick betalt för "kyrkans målning invändigt och en ny altartavla" (Bingsjö-Dådran O Ia:1). Altartavlan var således uttryckligen målad av Andersson, och det framgår att han vid detta tillfälle hade utfört ytterligare måleriarbete i kapellet, dock inte vad. År 1861 beskrevs altartavlan av Fredrik Reinhold Arosenius (1816-1870) som hade sett den på plats i sitt ursprungliga skick: "Altartavlan föreställer Kristi nedtagande från korset men är grovt utfört som det vill synas av någon inhemsk konstnär" (Landberg 1967). Något år senare, 1864, byggdes Bingsjö kapell om totalt: "en radikal ombyggnad, snarast en nybyggnad" (Hammarskiöld 2006:5, 8). Altaruppsättningen flyttades över till det nya kapellet men den kom vid renoveringen av kapellet 1881 att övermålas med en oljefärg i vitt. Efter detta har sedan altartavlans motiv ersatts ytterligare två gånger, åren 1932 och 1964 .

Efter övermålningen av altartavlan 1881 har det varit svårt att med säkerhet säga hur Anderssons måleri var beskaffat. Den osäkerhet som detta medfört har resulterat i att Andersson under 1900-talet har kommit att tillskrivas ett annat måleri som finns bevarat i kapellet, nämligen läktarens sju figurativa målningar (Garmo 1992). De har tillskrivits Andersson på grundval av kyrkoräkenskapernas generella formulering från 1843 och avsaknad av andra i arkivhandlingarna omnämnda målare. Det har dock även påpekats att läktarmålningarna troligen inte är så gamla som från 1843 och att det faktiskt finns uppgifter om en helt annan utpekad upphovsman (Landberg 1966:130ff). En närmare utredning kring läktarens historia visar att läktarmålningarna rimligen inte har något med Jonas Andersson att göra (LjM, opublicerad utredning).

I Bingsjö kapell finns dock annat måleri som i detta sammanhang är av stort intresse då de kan knytas till Mäx Jonas Andersson och visat sig vara tillkomna vid tiden för altartavlans tillkomst. Det är tre porträtt vars uttryck och framför allt underliggande skisser erinrar om de ansikten vi känner från de till Blåmålaren attribuerade verken (se fig. 7). Två av porträtten är ramade tillsammans, och anses föreställa Carl XIV Johan (1763-1844) och kronprins Oscar (1799-1859). Dessa var $185^{\circ}$ uppsatta som del av "en ryggspegel" till predikstolen och en uppgift från tiden angav att de var utförda av samma målare som altartavlan (Orkborn 1850:170). Detta nedtecknades av Isak Georg Sten- 

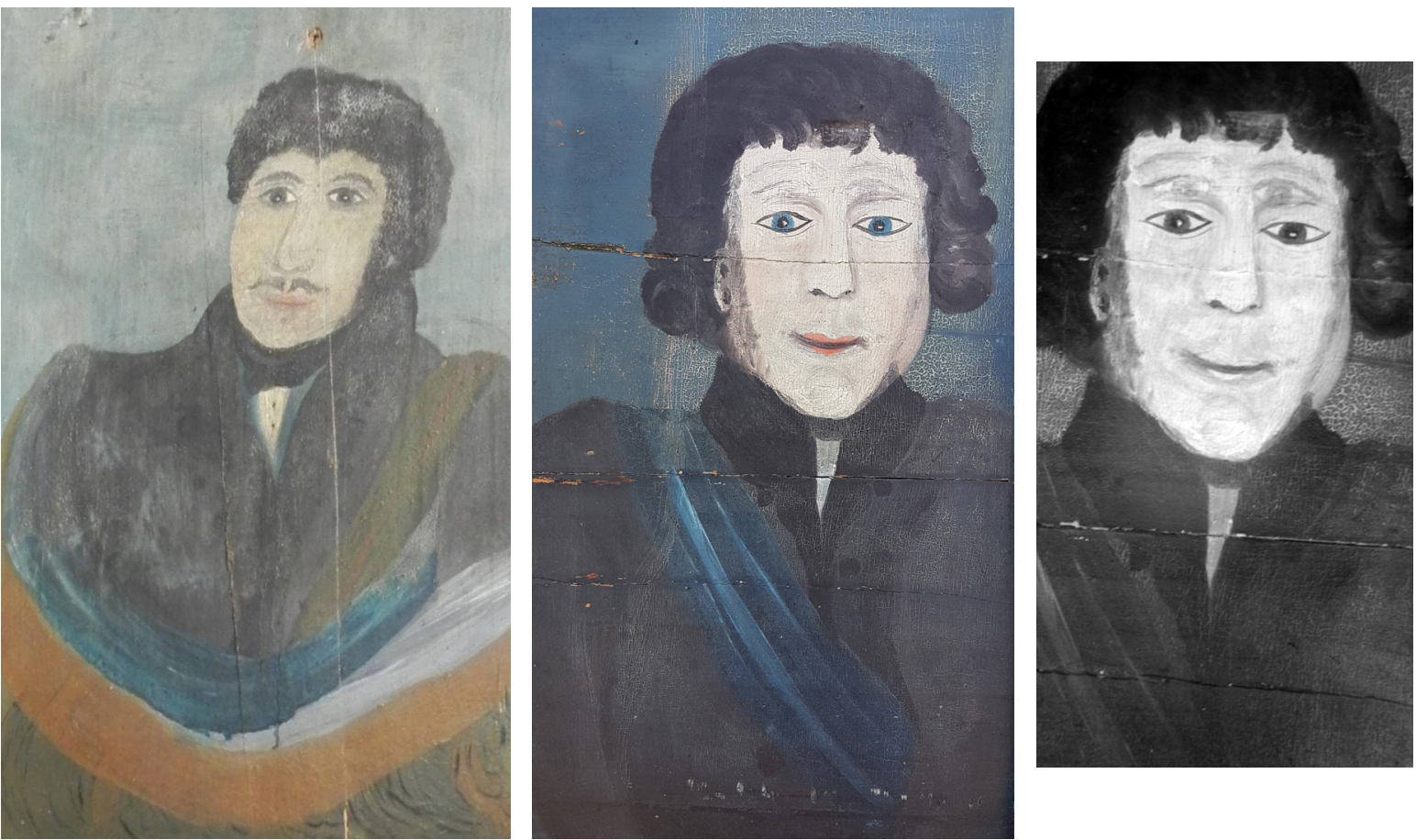

Figur 7 a-c (2.6.7 a-c): Två av de tre porträttmålningarna i Bingsjö kapell, vilka möjligen föreställer kronprins Oscar (1799-1859) samt kyrkvärden Nygårds Hans Persson (1772-1849) (t.v. och mitten). Foto: Anders Assis. Till höger ett IR-fotografi, där det framgår hur måleriet såg ut ursprungligen. Notera att den underliggande figuren under har stora likheter med andra figurer utförda av Blåmålaren. Foto: Ingalill Nyström

man (1816-1867), adjunkt i Rättvik mellan 1843 och 1850 (Landberg 1966:155). Att Stenman hade detaljkännedom om förhållandena framgår av att han angav konstnären som utbildad i staden och inte "en vanlig dalkarlsartist". Det är således tydligt att uppgiften avsåg tapetserargesällen Mäx Jonas Andersson och Stenman ansåg att måleriet höll en för sammanhanget låg kvalitet. Det tredje porträttet lär föreställa kyrkvärden Nygårds Hans Persson (1772-1849) ${ }^{87}$ (Garmo 1992).

Målningarna är inte daterade men de avbildade personernas levnadsbanor gör att de trots detta kan ringas in tidsmässigt. Porträttet på Nygårds Hans Persson bör ha utförts medan denne levde eller möjligen kort efter hans död, vilket daterar detta till senast omkring 1850. Att uppgifterna om kungaporträtten lämnats av Isak Georg Stenman $185^{\circ}$ ger samma bortre gräns för dem. Carl XIV Johan var kung i Sverige mellan 1818 och 1844 och fram till dess var Oscar fortfarande kronprins,

87. Enligt Landberg ska porträtten föreställa två kyrkvärdar och en okänd man (1966:131). De ska ha registrerats av Gerda Boëthius 1929. 
vilket talar för att dessa porträtt tillkommit före 1844. Hade de tillkommit i efterhand skulle Oscar rimligen ha angetts som kung istället för kronprins. Även om det inte går att belägga arkivaliskt så styrker detta att porträtten kan ha tillkommit i samband med det gamla kapellets nymålning 1843, och kan ha ingått i de arbeten som Mäx Jonas Andersson fick betalt för då. Det sätt, på vilka människoansiktena är målade på porträtten, och den penselföring med vilken deras klädedräkter är utförda, påminner starkt om detaljer i flera av Blåmålarens kända verk.

Även om fullständiga bevis saknas för att Blåmålaren är identisk med familjen Mäx Jonas Andersson och Karin Matsdotter talar flera fakta och indicier för en sådan tolkning. Kungaporträtten i Bingsjö kapell, med sina likheter med Blåmålarens stil och manér, kan genom Stenmans uppgifter säkert knytas till Andersson. Uppteckningen från Noresbo visar att Blåmålarens inredning där kan kopplas till kringvandrande dalfolk och mer specifikt till "en man och en kvinna".

Familjens kringflyttande liv matchar tidsmässigt och geografiskt samtliga verk som i dagsläget kan attribueras till Blåmålaren. Ett av de

Figur 8 (2.6.8): Spegel målad åt Anders Jonsson i Ljusdal 1848, vars föräldrar var dopvittnen för Mäx Jon Anderssons och Karin Matsdotters dotter Anna, född i Ljusdal 1847. Foto: Anders Assis

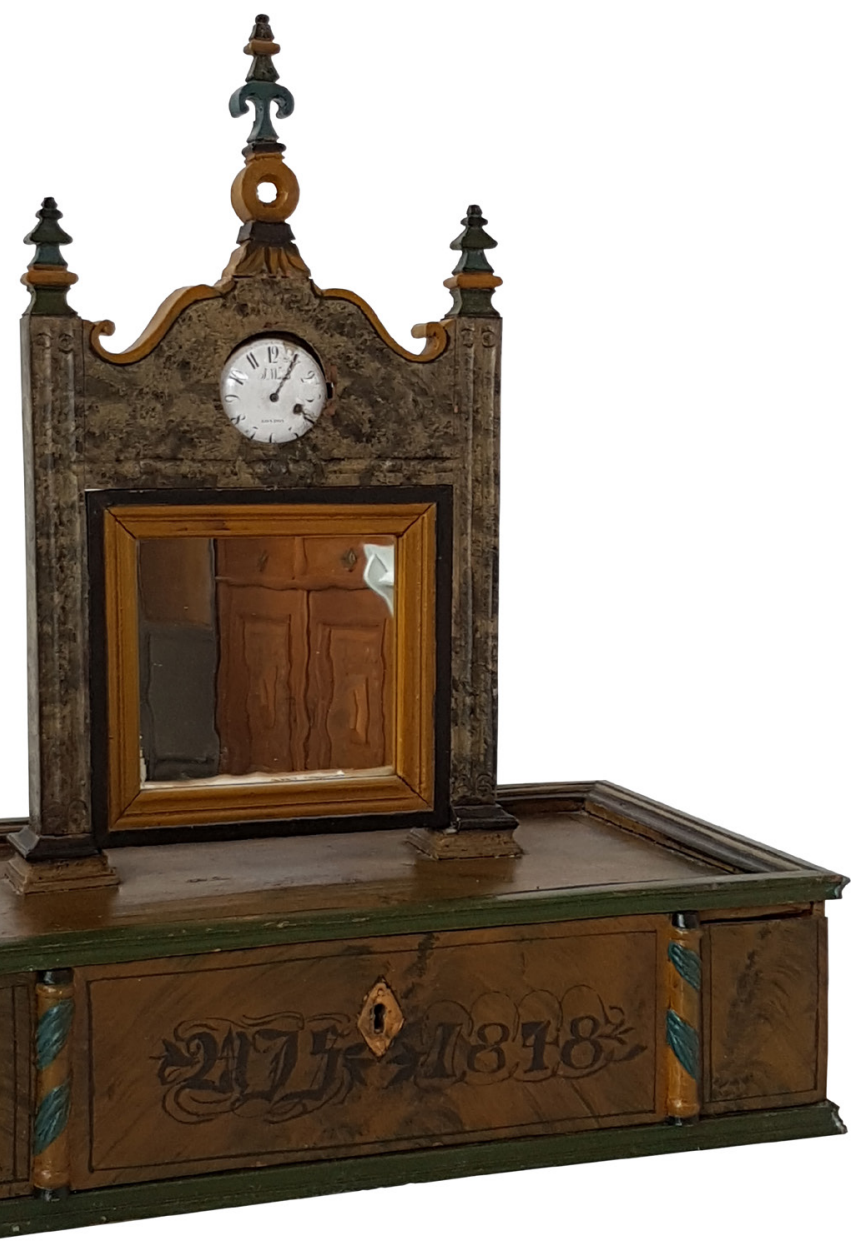


kända föremålen från Ljusdal, en liten rakspegel, går dessutom att knyta till målarfamiljens sociala kontext. Spegelns dekor anknyter starkt till den på sängen i Bommars (fig. 2 och 8). Spegeln målades 1848 till bondsonen Anders Jonsson (1826-1849) vars föräldrar var dopvittnen för Jonas Anderssons och Karin Matsdotters dotter Anna som föddes i Ljusdal 1847. Det bevisar i sig inte att de har målat spegeln, men icke desto mindre förs ett till Blåmålaren attribuerat verk in i deras sociala sammanhang. Och detta på en ort långt ifrån deras hembygd och vid en tidpunkt då de bevisligen var där.

Även i Alfta matchar Blåmålarens kända verk tämligen väl familjens olika geografiska hemvister. År 1864 skrevs familjen i Gundbo, en by i vars närhet många av Blåmålarens verk finns och två av barnen kom att gifta sig till Nordanå där inredningar av Blåmålaren finns dokumenterade. I inredningarna från Alfta tyder vissa detaljer på att fler målare kan ha varit delaktiga, vilket skulle kunna förklaras av att de äldsta barnen vid denna tid hade växt upp och då kan ha varit föräldrarna behjälpliga.

Om familjen Mäx Jonas Andersson är identisk med Blåmålaren så blir en viktig fråga hur deras måleri utvecklades under 1860-talet och efter det. De bodde i Alfta under hela den resterande delen av 1800-talet, och Jonas står skriven som målare hela tiden, och bör rimligen ha fortsatt vara aktiv efter 1860. Han kan då möjligen vara identisk med någon av de schablonmålare vilka har efterlämnat ett stort antal inredningar i Alftatrakten, tillkomna under denna period. Det figurativa måleriet blev omodernt efter 1860-talet och i flera av Blåmålarens verk finns betydande inslag av förhållandevis okomplicerat schablonmåleri. Detta blir dock frågor för framtida forskning.

Helt klart står att två av Hälsinglands världsarvsförklarade gårdar, Bommars i Ljusdal och Pallars i Alfta, bägge är dekorerade av samma målare eller målarfamilj. Blåmålaren uppvisade inte den flyhänthet $\mathrm{i}$ manéret som kännetecknade många andra dalmålare. Om familjen Mäx Jonas Andersson är identisk med Blåmålaren, tyder det på att Anderssons kunskaper, efter sina sex år i tapetserarlära, låg på andra delar av hantverket, vilket också stöds av andra personers utlåtanden om hans måleri i exempelvis Bingsjö kapell (Orkborn 1850; Arosenius 1862). Färgsättningarna i Bommars uppvisar möjligen målarfamiljens talanger, en uppenbar känsla och ett estetiskt sinne för hur olika målartekniker och material kunde kombineras till väl sammanvägda rumshelheter. Salen med sin intressanta kombination av handtryckta tapeter och scha- 
blonmålerier kan ses som resultatet av ett möte mellan en tapetserargesälls erfarenheter av inredning av borgarhem och en självmedveten bondekultur med starka egna stilpreferenser. Bommars är ett exempel på mötet mellan borgerliga och folkliga stilideal som hälsingegårdarnas inredningskultur ofta ger prov på.

\section{Referenser}

\section{Otryckta källor}

360-graders interaktiv vy av Bingsjö kapells interiör. Tillgänglig på: http://www. queenmedia.se/kyrkor/rattvik/5/

Alfta kyrkoarkiv, Husförhörslängder.

Bingsjö-Dådrans kyrkoarkiv, OIa:1, Handlingar angående kyrkan samt AI:1:7, AI:2:12.

Bjärtrå kyrkoarkiv, C:3:57.

Boda Kapellförsamlings arkiv, AI:6a:56, A I:7a:63 samt AI:8a:61.

Bingsjö Kapell, Bingsjö 2:14, Rättviks församling och kommun, Dalarnas län. Kulturhistorisk karakteristik. Upprättad 2006 av Rolf Hammarskiöld. Västerås stift.

Delsbo kyrkoarkiv. Födelse- och dopboken.

Falu Kristine kyrkoarkiv. AI:18:149, AI:20:71, AI:23:72 samt BII:1.

Ljusdalsbygdens museum $(\mathrm{LjM})$. Opublicerade utredningar. Utredning av kända uppgifter rörande läktaren i Bingsjö kapell, dess tillkomst och upphovsmän. Anders Assis 2017; Harald Grundells arkiv. Uppteckningar från 1929; Kerstin Sinhas arkiv. Inventeringar i Alfta i samarbete med Alfta hembygdsförening.

Ljusdals kyrkoarkiv. Ljusdal KI:6. Sockenstämmoprotokoll 1845 25/5 paragraf 1 samt Husförhörslängder och Födelse- och dopbok.

Länsmuseet Gävleborg, Gästrike-Hälsinge hembygdsförbunds arkiv, Ingemar Svenssons och Hilding Mickelssons inventeringsmaterial 1965-1971.

Nordiska museets arkiv (NM): Etnologiska undersökningar EU 861.

Nordiska museets bildarkiv: NM 172.O.m., 176.B.j., 176 B.n. och 176 B.o.

Ovanåkers kyrkoarkiv. Födelse- och dopboken.

Riksantikvarieämbetet. ATA. Oscar Svenssons arkiv.

Rättviks kyrkoarkiv. AI:12a:142, AI:15a:368 samt E1:1:193.

\section{Tryckta källor}

Ahlberg, Hakon \& Stefan Björklund (1996). Dalarnas kyrkor i ord och bild. Skrifter från Västerås stift. Falun: Kronvall information i samarbete med Västerås stifts information.

Andersson, Maj-Britt (2000). Allmogemålaren Anders Ädel. Stockholm: Prisma.

Andersson, Roland (1996). Rättviksmålare i österled. Hälsingerunor 1996.

Andersson, Roland, Margareta Andersson, Rune Bondjers \& Johan Knutsson (2007). Dalmåleri: dalmålarna, deras liv och verk. Dalarnas fornminnes- och hem- 
bygdsförbunds skrifter nr 38 . Falun: Dalarnas museum i samarbete med Nordiska museet.

Arosenius, Fredrik Reinhold (1862). Beskrifning öfver provinsen Dalarne, häfte 1, Rättvik. Falun.

Assis, Anders (2017). Jon-Pers i Nore, nytt ljus över Ädelmåleriet. Museivännen 2017:2. Ljusdal: Ljusdalsbygdens museum.

Berg, Leif, Eva Jacobson, Brita Nyqvist \& Barbro Parck (2002). Ljusdals socken, Letsbo, Bommars. I: Hälsingegårdar i fem socknar. Berg m.fl. Stockholm: Svensk byggtjänst.

Bergin, Christer (1995). Bäckpojkarna: ett målarkollektiv från Boda. I: Dalmålningar i jämförande perspektiv. Falun: Dalarnas museum.

Broström, Ingela (2011). Decorated Farmhouses of Hälsingland, Swedish World Heritage Nomination: Hälsingegårdar. Länsstyrelsen Gävleborg.

Brännberg, Gudrun F. (2007). Målare i Medelpad 1700-1890. Brännberg: Atremi. Kristianstad.

Envall, Karl-Erik (2003). Letsbo, Hedsta, Oppli, Hamran och Letsberg. Ljusdal: Tallåsen.

Garmo, Sune (1992). Bingsjö kapell. Västerås stifts kyrkobeskrivningskommittés skrifter nr 42. Rättvik: Västerås stifts kyrkobeskrivningskommitté.

Garmo, Sune (2011). Bingsjö kapell. Västerås stifts kyrkobeskrivningskommittés skrifter nr 87. Rättvik: Västerås stifts kyrkobeskrivningskommitté.

Hammarskiöld, Rolf (2006). Bingsjö kapell, kulturhistorisk karakteristik. Västerås stift.

Landberg, Georg (1966). Prästerna. I: Rättvik, del I:1, Socknen och kommunen. Västerås.

Landberg, Georg (1967). Kyrkor, kapell och prästgårdar. I: Rättvik, del I:2 Socknen och kommunen. Västerås.

Nyström, Ingalill (2012). Bonadsmåleri under lupp: spektroskopiska analyser av färg och teknik i sydsvenska bonadsmålningar 1700-1870. Diss. Göteborg: Göteborgs universitet, Tillgänglig på: http://hdl.handle.net/2077/30154

Orkborn, Jeremias (pseudonym för Stenman, Isak Georg) (1850). Hemseder i Dalom. I: Norden: Skandinavisk nationalkalender för år 1850.

Svensson, Ingemar \& Hilding Mickelsson (1967). Hälsingemålningar. LT. Stockholm.

Östlund, Manne (1953). Dekorativt inredningsmåleri Hälsinglands bondehem. Hälsingerunor 1953 . 